\title{
LAS GLOSAS DE NICOLÁS DE TREVET SOBRE LOS TRABAJOS DE HÉRCULES VERTIDAS AL CASTELLANO: EL CÓDICE 10.220 DE LA B.N. DE MADRID Y ENRIQUE DE VILLENA
}

Pilar Saquero Suárez-Somonte Tomás González Rolán Universidad Complutense

1. La eminente hispanista italina Margherita Morreale en su edición de Los doze trabajos de Hércules ha insistido' "en el interés de la obra de Villena para la historia de la tradición clásica, y sobre todo de la transmisión de los asuntos mitológicos y de su inserción en los ideales de la Edad Media"s.

En efecto, entre las obras de la Antigüedad utilizadas por Villena destaca el De Consolatione Philosophiae de Boecio, obra que le sirvió como modelo para establecer el número y disposición de los trabajos del héroe mítico ${ }^{2}$ : "Por diversas maneras la orden de aquestos trabajos han los actores variado, algunos poniendolos segunt orden natural e de tienpo, otros segunt orden artifiçial e de dignidat. Onde la mas comun e aprovada es la que boeçio a tenido en el su quarto libro de consolaçion en el metro final siguiendo la orden de dignidat...»

Con estas palabras Enrique de Villena se está refiriendo al metro séptimo del libro cuarto del De Consolatione de Boecio ${ }^{3}$ que dice así (vv. 13 ss.):

Herculem duri celebrant labores Ille Centauros domuit superbos,

15 Abstulit saevo spolium leoni

$$
\begin{aligned}
& =1{ }^{\text {er }} \text { trabajo } \\
& =2 .{ }^{\circ} \text { trabajo }
\end{aligned}
$$

'Enrique de Villena, Los doze trabajos de Hércules, Madrid, p. IX.

Op. cit., pág. 16.

"Boethius, ed. de H. F. Stewart, E. K. Rand, J. J. Tester, "The Loeb Classical Library», Londres, 1973, págs. 380-383. 
Fixit et certis volucres sagittis Poma cernenti rapuit draconi Aureo laevam gravior metallo Cerberum traxit triplici catena

20 Victor immitem posuisse fertur

Pabulum saevis dominum quadrigis.

Hydra combusto periit veneno,

Fronte turpatus Achelous amnis

Ora demersit pudibunda ripis.

25 Stravit Anteum Libycis harenis,

Cacus Evandri satiavit iras

Quosque pressurus foret altus orbis

Saetiger spumis umeros notavit. Ultimus caelum labor inreflexo

30 Sustulit collo pretiumque rursus

Ultimi caelum meruit laboris.

$$
\begin{aligned}
& =3 .^{\circ} \text { trabajo } \\
& =4 .^{\circ} \text { trabajo } \\
& =50^{\circ} \text { trabajo } \\
& =60^{\circ} \text { trabajo } \\
& =70^{\circ} \text { trabajo } \\
& =80^{\circ} \text { trabajo } \\
& =90^{\circ} \text { trabajo } \\
& =10^{\circ} \text { trabajo } \\
& =11 .^{\circ} \text { trabajo } \\
& =12 .^{\circ} \text { trabajo }
\end{aligned}
$$

Como puede observarse inmediatamente, el autor latino reseña brevemente los doce trabajos de Hércules sin entrar en la descripción pormenorizada de su contenido, hecho que sí encontramos en la obra castellana. Es, pues, imposible que, por ejemplo, sea sólo el verso 15 de Boecio ( $A$ bstulit saevo spolium leoni) al que se refiere don Enrique cuando al tratar del segundo trabajo nos dice": "El segundo trabajo fue cuando Hércules mato el león en la selva o montaña espesa de árboles nonbrada por los de aquel tienpo nemea. De aquestos fabla boeçio e muchos istoriales e poetas...»

Este hecho no escapó a la fina observación de $\mathrm{M}$. Morreale ${ }^{5}$, quien se pregunta si no usería éste un Boecio glosado de los muchos que circularon en la Edad Media. Una glosa extensa de los mencionados versos de la Consolación explicaría no sólo el armazón de los Doze trabajos, sino también buena parte de su contenido narrativo. Pero el hecho es que las glosas de Trevet y otras que he podido consultar son demasiado sucintas para que se puedan considerar como fuente principal de la "historia nuda" ${ }^{6}$.

Op. cit., pág. 23.

'Op. cit., págs. XXI.

- Villena divide su libro en doce capitulos que corresponden a otros tantos trabajos de Hércules y cada capitulo en cuatro partes: "Sera este tractado en doze capitulos partido e puesto en cada uno un trabajo de los del dicho hercoles por la manera que los estoriales e poetas los han puesto. E despues al expusiçion alegorica e luego la verdat de aquella istoria segunt realmente contesçio. Dende seguirse a la aplicaçion moral a los estados del mundo e por enxenplo al uno de aquellos. Por eso cada capitulo en quatro parrafos sera partido, en el primero la estoria nudamente poniendo, en el segundo las obscuridades declarando, en el terçero la verdat de la ficçion apartando, en el quarto el artifiçio de la aplicaçion esenplando». (pág. 10 de la ed. citada). 
M. Morreale admite, pues, que Villena ha podido utilizar una glosa a la Consolación de Boecio, pero descarta por demasiado breve la glosa de Nicolás de Trevet, aspecto éste último criticado con dureza por R. G. Keightley': "Dr. Morreale may have acted too hastily in thus dismissing as likely sources Nicolas Trevet's commentary on Boethius and others derived from it, although it is perfectly true that the narratives they contain are very brief.»

Una apoyatura externa en favor de esta hipótesis se encuentra, según Keightley, cuando se analizan las fuentes utilizadas por Villena en otras obras suyas y se descubre que cita y se sirve del Comentario de Trevet en el Tratado de la consolaçion de 1422 y en el Comentario a la Eneida de Virgilio concluido en 1427 , fecha en la que compuso primero en catalán, el 3 de abril, y luego en castellano, el 28 de septiembre, la obra sobre Hércules.

Pero el elemento decisivo procede del cotejo de las glosas de Trevet con el tratado de Villena, si bien surge inmediatamente el problema de determinar si la deuda es directa o a través de alguna o algunas de las versiones en romance de la Consolación de Boecio que, acompañadas de glosas, circularon por los distintos reinos de España en el siglo XV.

Por lo que se refiere a la relación de Villena con las glosas de Trevet el citado autor sostiene que una comparación de pasajes relevantes ${ }^{8}$ : «in fact reveals that there are at least four Labours in Los doze trabajos de Hércules for which the commentaries appear to furnish the basic structure and possibly some of the details of the istoria nuda or the verdad.»

En cuanto a las traducciones romances de Boecio acompañadas de glosas, la que guardaría una más estrecha relación con Villena sería la que se encuentra ahora en la Biblioteca Nacional de Madrid con el número 10.220 y que algunos han atribuido a Pero López de Ayala": «Enrique de Villena used a commentary on Boethius either by Trevet or derived form Trevet's when writing Los doze trabajos de Hércules, the text he employed may have been related to that attributed to Pero López de Ayala, and its main function was to establish the identy of the beasts and figures alluded to in Boethius's poem.»

En cierta medida nos parecen convincentes, aunque no definitivos, los argumentos ofrecidos por el estudioso australiano sobre la dependencia de Villena respecto de algunas glosas de Trevet, pero no podemos estar de acuerdo con la segunda parte de su conclusión, la que se refiere a la relación entre Villena y la traducción atribuida a López de Ayala.

' «Boethius, Villena and Juan de Mena», BHS, LV, 1978, págs. 189-202; del mismo autor «Enrique de Villena's Los Doze Trabajos de Hércules: A Reapraisal», JHP, 3, 1978, pág. 4968.

Op. cit., pág. 192.

Op. cit., pág. 200. 
Ahora bien, para establecer relaciones claras de dependencia o independencia entre los textos es necesario conocerlos y en este sentido presentaremos las glosas latinas de Trevet y las que acompañan a las traducciones castellanas de Boecio de los códices de la Biblioteca Nacional de Madrid n. $^{\text {os }} 174,9.160,10.193$ y 10.220 .

\section{Las glosas de Nicolás de Trevet y sus Traducciones Castellanas}

El dominico inglés Nicolás de Trevet, nacido en Somerset entre 1258 y 1268, se educó en París y vuelto a Inglaterra se dedicó hasta su muerte en Oxford (ca. 1334) a la enseñanza y a la elaboración de comentarios de autores clásicos como Virgilio ${ }^{10}$, Tito Livio ${ }^{11}$, Séneca ${ }^{12}$ y tardíos como Boecio.

Se trata este último de uno de los varios comentarios que se hicieron en la Edad Media sobre el De consolatione philosophiae $e^{13}$ y del que poseemos abundantes testimonios ${ }^{14}$, entre ellos el que se halla en el códice f.I.3 de la Biblioteca de El Escorial ${ }^{15}$, que entre los folios $46^{r}-46^{\vee}$, al explicar los versos de Boecio citados anteriormente dice así:

[fol.46'] De Hercule cuis describit duodecim labores quibus fingitur

10 Cf. A. A. Nascimento, «Um comentador medieval das Bucólicas de Virgilio. Nicolau Trivet", Euphrosyne, XI, 1981/82, 180-6; A. A. Nascimento-J.M. Diaz de Bustamante, Nicolás Trivet Anglico, Comentario a las Bucólicas de Virgilio, Universidad de Santiago de Compostela, 1984.

"Cr. Ruth Y. Dean, "The earliest known Commentary on Livy is by N. Trevet", en Medievalia et Humanistica, III, 1945, 86-98; C. J. Wittlin, Pedro López de Ayala, Las décadas de Tito Livio, vol. I, Barcelona, 1983, págs. 25 ss.

${ }_{12}$ Cf. K. A. Blüher, Séneca en España, Madrid 1983; E. Franceschini, «Glosse e commenti medievali a Seneca tragicon, en Studi e note di filologia latina medievale, Milán, 1938, 1-105.

"Cf. P. Courcelle, La Consolation de la Philosophie dans la tradition littéraire; antécédents et posterité a Boéce. París 1967; F. Troncarelli «Per una ricerca sui commenti altomedievali al De Consolatione di Boezion, Miscellanea in memoria di G. Cencetti, Torino 1973, 863-880; C. Leonan, «I commenti altomedievali ai classici pagani da Severino Boezio a Remigio d'Auxerre", en La Cultura Antica nell'Occidente latino dal vil all'xI secolo, Spoleto 1975, 459-504; A. J. Minnis-A.B. Scott-D. Wallace, Medieval Literary Theory and Criticism c. 1.100-c. 1.375. The Commentary-Tradition, Oxford 1988, págs. 314 y ss.

${ }^{14}$ Cf. Th. Kaepeli, Scriptores Ordinis Praedicatorum Medii Aevi, III, Roma 1981, págs. 187 y ss.

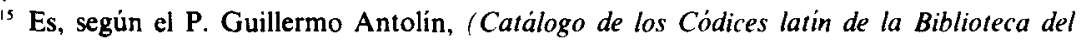
Escorial, vol. II, Madrid, 1911, págs. 129-30) un códice en pergamino, de 55 folios, de $395 \times$ $260 \mathrm{~mm}$. de medida, y cuyo titulo en este: Boethii de Consolatione Philosphiae cum expositione Fr. N. Nicolai Treveth $O$. P.; al final trae la fecha en que terminó de copiarse: Et completus fuit $M C C C C X$ die martis nono mensis maii.

En la misma biblioteca se encuentra otro códice, el S-II-22, de Boecio con comentarios, pero éstos no son los de N. Trevet. 
mouisse celum. Istos autem labores aliter enumerat Claudianus De raptu proserpine libro tertio et etiam Ouidius Methamor. libro quinto. Sicut ergo diuersi labores, scilicet suscepti spe glorie, celebrant, id est celebrem et gloriosum reddunt Herculem.

[1.] Cuius primum laborem ponit domationem centaurorum. Dicitur: Ille,scilicet Hercules, domuit centauros superbos, confidentes de propria fortitudine, per quam alios contempserunt. Centauri sunt quedam monstra ex parte homines et ex parte equi, quos poete fingunt genitos ex nube ut patuit supra libro tertio metro ultimo. Verum tamen an solum sint huius modi monstra fictione poetica introducta an natura etiam talia producat. Hos dicitur Hercules domuisse quia multipliciter eos deuicisse fingitur; cum enim ad ludum palestre conuenissent in monte falce ibi cum eis congressus Hercules eos usque ad efusionem cruoris postrauit, unde Claudianus in tertio libro de raptu Proserpine prostratis maduit nubigenis falce uulnerati etiam sagittis eius cum se lauissent in Anagro fluuio aquam eius amaram et impotabilem propter toxicum sagittarum reddiderunt...

Secundum autem veritatem ystorialem Yxion primus in Grecia centum milites adunauit cum quibus infestabant Greciam; qui equites cum primum uisi sunt ab indoctis insidere equos unum animal ex equo et homine reputati sunt; et dicti sunt centauri quia centum erant et quia ut aura uelocissime currentes, totam terram deuastabant, qui postea ab Hercule deuicti sunt.

[2.] Abstulit spolium seuo leoni. Sciendum est proinde Nemea silua fuit quidam leo pessimus, cuius terror totius regionis homines inuassit, quem aggressus Hercules pro liberatione patrie interemit et excoriauit et pellem abstulit et hic fuit secundus labor.

[3.] Tertium laborem tangit cum dicit Fixit et uolucres, id est Arpias, certis sagittis, id est certe sagitando. Hec fabula talis est: Phyneus filios suos, qui de stupro nouercam suam acusauerant, cecauit; propter quod iudicio deorum ipse quoque cecus factus est et apposite sunt ei Arpie, id est uolucres quedam, uirgineo uultu que mensam eius fedebant et cibum eius auferebant; quas Hercules sagitando fugauit [fol.47 $]$.

[4.] Poma cernenti. Quartum laborem tangit <cum> dicit: Rapuit poma draconi cernenti, id est custodienti, grauior scilicet factus, id est hiis grauem leuam aureo metallo uorat habitum coligentis, qui destra coligit et leue supportandum imponit. Fabulam istam diffusius tangit Lucanus libro VIIII dicens. Fuere enim septem filie Athalantis habentes ortum aureum, autem habentes arbores producentes poma aurea quorum custodia comissa erant draconi insomni; superueniens autem Hercules sopito dracone rapuit poma aurea, que portauit Euristeo regi Argolicorum. 
[5.] Quintum laborem tangit cum dicit: Cerberum, id est canem infernalem, traxit ab inferis triplici catena; de isto Cerbero, qui alio nomine dicitur Tergeminus, dictum fuit libro primo metro ultimo. Quomodo autem hunc canem traxerit Hercules fingitur sic: Pyricous uolens sibi disponsare reginam inferni, Herculem et Theseum et alios uiros fortes assumpsit. Venientibus autem illis ad inferos, ne Cerberus, qui ianitor inferni dicitur, latratu suo eos impediret, Hercules eum uinxit catena adamantina, ut dicit Ouidius Metham.libro septimo, quam propter tria capita oportuit triplicari, et eum traxit ad superos qui prouocatus ira latratu impleuit auras superas et sparsit aconitum uenenum.

Comestor in Ystoria Scolastica super librum Iudicum capitulo tertio dicit quod Orcus rex molosorum ingentem canem habuit nomine cerberum, qui Piritoum uolentem rapere Proserpinam uxorem Orci deuorauit et Theseum deuorasset nisi Hercules superueniens ipsum liberasset.

[6.] Sextum laborem tangit <cum > dicit qui huius modi erant. Fingitur quod Diomedes, rex Tracie, equos suos humana carne pascebat, unde in pabulum eorum hospites suos interficiebat. Ad quem ueniens Hercules ipsum equis eisdem in pabulum prebuit et equos occidit, unde dicit Ouidius Metham. libro quinto in persona Herculis: Quidque terras equos...

Secundum ueritatem ystorie Diomedes tyrannus quidam erat tenens multos equites et nutriens equas, que secundum Plinium perniciosiores sunt in currendo quam equi, qui pro pabulo equarum et sustentatione hominum armigerorum rapiebat bona ciuium suorum et eos depauperabat, ideo dicitur dedisse homines in pabulum equis suis, per Herculem uero coactus est et rapiram dimittere et de propriis bonis equitibus exhibere; in quo tandem defecit et inops factus est, propter quod dicitur eum deuoratum ab equis suis.

[7.] Septimum laborem tangit cum dicit Ydra. Fabula talis est: Fingitur in Lernea palude fuisse quidam serpens habens plura capita quorum uno succiso nascebant tria alia capita. Quem aggressus est Hercules sagitando et cum se proficere non uideret, adunata congerie lignorum ipsum combussit, unde dicit Ydra periit combusto ueneno, id est uenenoso combusto. Ysidorus. Ethim. libro II capitulo De portentis dicit Ydram fuisse euomentem aquas uastantes uicinam ciuitatem, in quo uno meatu clauso multi erumpebant, quod Hercules uidens loca illa exussit et sic aque clausit meatus.

[8.] Octauum laborem tangit cum dicit Fronte turpatus, cuius fabula ponit Ouidius Meth. libro nono; dicit quod fuit quedam uirgo nomine Deyanira per quam certauerunt simul Hercules et Achelous, qui diu luctantes tandem Hercules uincere cepit. Videns autem Achelous non posse resistere uiribus conuertit se ad artem suam per quam mutari consueuit in diuersas formas, et mutatus in serpentem lapsus est de manu Herculis; quem iterum Hercules arripiens cum fere strangulasset eum, subita mutatione factus est thaurus cum quo con- 
grediens Hercules ipsum deyciendo in terram fregit cornu eius, pro quo uerecundatus Achelous latuit in fluuio. Et hoc est quod dicit Achelous amnis, id est fluuius ille turpatus fronte propter fractionem cornu demisit ripis ora pudibunda latens, scilicet per pudorem.

Huius fabule uerita[ti]s talis est: Achelous fluuius est positus inter Greciam et Calidoniam, in qua regnauit Oeneus, cuius filiam Deyaniram cum uellet Hercules in Greciam transferre non potuit propter fluuium oppositum, cuius desiccauit unum brachium, ideo dicitur ei abstulisse unum cornu.

[9.] Nonum laborem ponit <cum> dicit: Strauit, scilicet luctando, Anthe um, Gigantem, arenis libicis. Hanc fabulam ponit Lucanus libro quarto; dicit quod Antheus gigas erat terra progenitus, cui talis uirtus erat quod si quando ex fatigatione debilitaret, statim ex tactu terre reparabat uires. Hic cum exerceret tyrannidem in Libia aduenit Hercules et congressus cum eo diu luctatu ancipiti se tenebant, quociens enim se debilitari sensit Antheus sponte cadebat et renouata uirtute surgebat, quod percipiens Hercules ipsum a terra eleuauit et super pectus suum tenendo strinxit quousque emisit spiritum. Quod hic dicitur de uirtute Anthei, non uidetur fictio poetica sed ueritas hystorica......

[10.] Decimun laborem tangit cum dicit Cacus Euandri saciauit iras, cuius fabulam ponit Virgilius Eneydos libro octauo. Cacus fuit quodam monstrum euomens ignem per os, cuius pater fingitur Vulcanus, quod manebat in Auentino monte spolians et occidens homines et per hoc Euandrum, qui in terra illa regnabat multum inequietans cum autem redieret Hercules de $Y_{S-}$ pania ducens armenta boum. Iste Cachus quattuor thauros et quattuor uacas ei furatus est et, ne furtum pateret, traxit illos per caudam in antrum suum, ut non apparerent illinc inisse sed illinc redisse. Hercules autem querens armentum suum per mugitum unius bouis comprehendit furtum et accedens ad speluncam Caci ipsum extraxit et interfecit, ex quo pacata est terra Euandri, nam iste Cacus fuit latro Euandri. Incendio uastauit, ideo dictus est euomere ignem et filius Vulcani, quem postea Hercules interfecit.

[11.] Undecimum laborem tangit cum dicit Quosque pressurus, unde notatus est quod in Archadia erat aper quidam regionem uastans quem cum agitaret Hercules ille insultans in Herculem humeros eius spuma signauit, quem tandem Hercules interfecit. Dicit ergo quod setiger, id est aper gerens setas, notauit, id est signauit, spumis humeros....

[12.] Duodecim et ultimum tangit cum dicit Ultimus, unde sciendum est quod Atlas fingitur fuisse quidam gigas supportans celum, qui in Gygantomachiam, id est pugna Gygantum contra deos, de qua fit mentio in Ouidio Metham. primo et secundo, fatigatus rogauit Herculem, qui post alios labores ad eum uenit, ut celum supportaret donec ille gigans aliquantulum respiraret. Qui suponens se tanto oneri illud inflexibiliter suportauit, unde et per hoc celum 
promeruit, unde dicit ultimus labor Herculis fuit quod sustulit, id est supportauit, celum collo inreflexo rursusque meruit celum, precium ultimi laboris.

Huius fabule ueritas est quod Athlas astrologus erat qui dicitur supportare celum quia celestium scientiam supportauit. Quo respirante hercules Celum supportat, quia post mortem Athlantis, qui est respiratio et requies phylosophis, a laboribus huius mundi Hercules contemplationi celestium uacauit. Et hic fuit ultimus labor quia theorica etsi dignitate precedat practicam in tempore, tamen est posterior, quia prius domanda sunt monstra uitiorum per practicam quam quieti theorice possit uacari.

Notatur quod non est credendum Herculem fuisse unum hominem cui omnia predicta euenerint, tamen quia beatus Augustinus De ciuitate Dei, libro octauo capitulo duodecimo dicit quod alius fuit Hercules cui atribuuntur duodecim ingentia facta et qui Antheum afrum interfecit. Dicit etiam ibi multos fuisse Hercules et potest esse quod erant cognomina magnorum uirorum qui uirtute et audacia quasi singulares uidebant, unde Augustinus dicit eodem libro capitulo 13 quod Sanson propter mirabilem fortitudinem putatus est Hercules et Yason qui primitus dicitur adinuenisse nauigium et ante bellum troyanum etiam Troyam cepisse cognominatus est Hercules ut patet in ystoria Darethis Frigii De bello troyano, de quo etiam uidetur inteligi illud Ouidii Metham. libro quarto; dicit Menia que forti troyana sub Hercule cepi; unde etiam quedam atributa huic Herculi a quibusdam sub alio nomine dicuntur facta, ut puta interfectio apri Archadie dicitur facta a Meleagro ut patet libro octauo a Ouidii Metham. et fuga Arpiarum a filiis Boree Zeto et Calay ut patet libro septimo eiusdem.

Item nota quod omnes labores sunt positi uel $<u t>$ nudam sonant ystoriam, ut secundus de leone et undecimus de apro, uel ystoriam cum fabula mixtam exceptis duobus, scilicet tertio de fuga Arpiarum et quarto de raptu pomorum aureorum, qui solum spectant ad integumentum morum, unde quia non sunt supra expositi hic exponemus. Et igitur sciendum quod Hercules notat uirum sapientem, dicitur enim ab her grece, id est lis latine, et cleos, id est gloria quia uir sapiens pro adipiscenda gloria luctere habere cum uiciis. Taliter autem uir sagitis suis, id est doctrinis et sententiis suis fugat Arpias, id est rapacitatem auaritie, arpo enim grece, id est rapio a Fyneo ceco, id est auaro. Auaritia enim affectum cecat et sic arpie fedant mensam, sic rapacitas facit uictum inmundum quoniam est de male ablato. Talis etiam uir sapiens sopito dracone, id est sensualitate, aufert poma aurea, id est acquirit delectationem sapiencie que est possessio filiarum Athalantis, id est uirtutum, quas gignit celestium contemplator. Alie fabule ystoriales sunt supra sufficienter exposite... Et alludit, continuando fabulas de Hercule, ei quod fingitur libro nono Ouidii Metham. de deificatione eiusdem. Ipse enim deuicit omnia monstra terre et tandem in celum translatus fulget in quibusdam stellis que designant eum cum claua et spolio leonis, ut euidentius patet in libro De ymaginibus stellarum.

En este comentario Trevet afirma de modo claro que los trabajos se- 
gundo y undécimo se prestan solamente a la pura y escueta descripción de un hecho, es decir, sonant nudam ystoriam.

Los trabajos primero, quinto, sexto, séptimo, octavo, noveno, décimo y duodécimo además de la ystoria incluyen la fabula, o mejor la ficción poética; otros, en fin, como el tercero y cuarto "solum spectant ad integumentum morum".

Dentro del segundo grupo, es decir, los que a la ystoria añaden la fabula, hay una serie de trabajos, concretamente el primero, quinto, sexto, séptimo, octavo y duodécimo, en los que la fábula es seguida de la exposición de lo que Trevet llama ueritas historica o ueritatem ystorie.

Así, pues, de las distintas interpretaciones dadas por la Antigüedad sobre el origen y naturaleza de las divinidades y que se conocen con el nombre de evemerismo, alegorismo y astralismo, Trevet las conoce y aplica tanto al personaje como a sus hazañas.

La interpretación evemerista corresponde al apartado de la ueritas historica, el alegorismo al del integumentum morum, el astralismo al momento en que, después de vencer a todos los monstruos que se le ponen delante, Hercules in celum translatus fulget in quibusdam stellis...

R. G. Keightley ${ }^{16}$ ha señalado la coincidencia del término "nuda ystoria» que aparece en Villena con el correspondiente latino de Trevet, pero un análisis detenido de la estructura organizativa de uno y otro revela enormes diferencias. Así, mientras Villena, después de la "historia nuda", aplica sistemáticamente a todos y cada uno de los trabajos la interpretación alegórica en el apartado que llama "Declaraçion», y la interpretación evemerista en la sección denominada «Verdad», Trevet, en cambio, restringe la interpretación alegórica a los trabajos tercero y cuarto, y la evemerista al primero, quinto, sexto, séptimo, octavo y duodécimo.

Han tenido como modelo el texto de Trevet anteriormente reproducido las glosas explicativas a los trabajos de Hércules que se encuentran en los

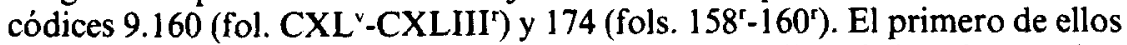
lo dice expresamente en el fol. $1^{\text {r: }}$ :Aqui comiença el libro de boeçio seuerino senador de rroma el qual fizo estando preso por mandado de theodorico rrey de los godos e es llamado este libro de conssolaçion e fue declarado por vn doctor en ssanta theologia que ouo nonbre frey nicolas trebet de la orden de los frayres de santo domingo...».

Con todo, la traducción, respecto al modelo latino, es bastante libre y muy resumida.

Otro tanto se puede decir de la que se encuentra en el códice 174 cuyo autor no acierta siempre a dar el sentido exacto y correcto a su traducción,

${ }^{16}$ Op. cit., pág. 194. 
como ocurre en el pasaje de las Arpias en donde Fineo ciega a su segunda mujer y no a sus hijos.

\section{Glosas INDEPENDIENTES DE TREVET}

De Pedro de Valladolid ${ }^{17}$ es la traducción de la obra de Boecio que se conserva en el códice 10.193, tal como se indica en el colofón (fol. LXXXII ${ }^{v}$ ): «Este libro fizo pedro de valladolid criado del señor rey de nauarra e oficial suyo de pararle su tabla en que comiese e las cortinas en que oya misa e fizolo en la villa de alcañiz en el año de mill e quatroçientos e treynta e seys años en el mes de setienbre ha veynte e vn dia andados...».

Las glosas que se encuentran entre los folios $\mathrm{LXIX}^{\mathrm{v}}$ y LXXI ${ }^{\mathrm{v}}$ hacen una breve mención de los doce trabajos de Hércules para extenderse más ampliamente en su aplicación alegórica:

[fol. LXIX ${ }^{\eta}$ ] E dezirte he avn los trabajos que muy valiente mente ansi como onbre sabio e virtuoso sufrio ercoles por eso que le puedas ressenblar, los quales trabajos rrecuentan los antiguos e algunos son verdaderos e otras son fablas.e a declaraçion de aquesto es cosa nottoria que ercoles fue fijo del rey de gresçia e fue filosofo mui grande e mui sabio e mui çierto e muj auissado e omne fuerte e rezio de su persona. E dizese que ouo madrasta la qual le queria gran mal e so semejança de bien fazia su poderio que le muriese por lo qual aconsejaua al dicho rey marido suyo e padre de ercoles que le enbiase a las cosas deyuso escriptas por tal que muriese o que se salliese de toda la tierra e esto por tal que sabia que era mui obediente a su padre e que no le saldrie de mandamiento e que faria luego que le fuese por el mandado. E primera mente fue enbiado para adomar los çentauros los quales son figurados medio cauallo e medio onbre saluajes e son muy feos, aquestos fueron domados por ercules que les prometio que la su partida bestial les faria tornar umanal. E depu [fol. LXX'] es fue enbiado para matar vn leon mui fiero e mui cruel mas que ninguno otro e fuele mandado que leuase la su piel.

E despues fue enbiado que perseguiese a las arpias con saetas de las quales se dize en las fablas que son donzellas virgines que buelan ansi commo aues e son seydas enbiadas para punir a fineo que es çiego de la vianda del qual toman alguna e la otra parte que queda ensuzian con sus suziedades.

Cf. M. Schiff, La bibliothèque du Marquis de Santillane, Paris, 1905 (reimp. Amsterdam, 1970, págs. 179-180). 
E despues fue el mandado que tomase e traxiese de las milgranas o mançanas de oro que eran en el vergel de las espidas la quales son acomendadas para guardar ha vn dragon fuerte malo al qual ercules apremio contra tierra con fuerça e pesadumbre de la su mano esquierda e con la derecha tomo de las mançanas.

E la quinta vegada fue enbiado para prender antiferus que era portero del infierno al qual prendio e lo traxo atado con tres cadenas.

La sesta vegada fue enbiado a bursides por tal que albergase en su casa el qual por gran malisçia que auia mataua todos los sus huespedes.e despues que eran entrados en su cassa no salien: aqueste fue muerto por ercules e dio la carne ha comer a las bestias.

La VII vegada fue enbiado a la ydra en la paluda en la qual auia vna sierpe mui cruel e peligrosa al agua e la dicha sierpe auia vista muy espantable e fazia muy gran dapño a una cibdat la qual era çerca della.ercules dio por consejo a las gentes de la çibdat que las yeruas e los arboles que estauan açerca e entorno de la ydra fuesen del todo arrancadas e los montes asi mismo que eran en torno de alli que fuesen quemados atanto quanto pusible fuese e ansi que quando llouiese fuese enbeuida el agua de la lluuia e consumada por la tierra quemada, e demas de esto con su artefiçio fuego griego que mato a la dicha sierpe que abitaua en la dicha agua e las fuentes se secaron por razon de los montes que eran quemados e consumauan el agua de la lluuia e por las plantas arrancadas.

La otaua le fue mandado que partiese en dos partes el rio llamado arthelon el qual era muy grande e muy poderoso e fazia a menudo grand dapño.

La IX vegada fue enbiado contra entheo giguante que era en libia muy mal onbre e fuerte batallador, aqueste fue vençido e muerto por ercoles.

$\mathrm{La} X$ vegada fue enbiado contra $\mathrm{cac}^{\mathrm{us}}$ que era gran ladron e malo que auia tomados los bueyes del rey, aqueste fue muerto por ercoles.

La onzena [fol. $\mathrm{LXX}^{\mathrm{V}}$ ] vegada fue contra un puerco saluaje mui grande ademas e muy malo en tanto que non temia cossa e matolo ercoles con gran enginio e gran çerteza.

La dozena vegada fue quando le enbiaron que sostouiese el çielo en lugar del archelante por la qual cosa commo fue obediente e no dubdo ni lo refuso, meresçio que fuese puesto e dado lugar entre las estrellas del çielo.

Moral mente declarando las dichas ystorias por ercoles es entendido el sabio e virtuoso e que ha virtud de fortaleza el qual deue ser aparejado de sofrir muchos e diuersos trabajos e de ser puesto en muchos peligros por conseruaçion de virtud e de ser fijo de rey.ca el entendimiento es ansi como el rey synse el qual non puede ninguno regir a si mesmo ni a otro, la mano derecha es la sensualidad que faze su poderio que le faga desuiar con cosas peligrosas so semejança de bien: aquesta persona virtuosa e sabia deue domar los çentauros.conuiene a saber los mouimientos de la sensualidat que son medio bestiales rreduziendolos con la razon e despues deue destroyr en 
si e en otros todo orgullo que es entendido por el leon. E despues deue perseguir e contrastar a las roberias que no sean fechas por ninguno que son entendidas por las arpias, las quales segun que dize fulgençio son tres conuiene saber cobdisçia tomar e asconder e son dichas virgines por tal como no fazen prouecho a si ni a los otros e supita mente lo an e supita mente lo pierden por la qual cosa son conparadas ha aues bolantes e son enbiadas para punir a fineo çiego por el qual es entendido el ome auariento el qual es çegado por auariçia e tomanle parte de la su vianda que no se osa fartar e ensuzianle la otra parte ca no osa comer cosas de preçio nin de valor mas las mas mesquinas e mas menguadas que pueda fallar por tal que no le cuesten mucho y son guisadas e aparejadas mal e suzia mente e comen en suziedat e todo esto faze por que no le calga despender nin gastar.por las milgranas o mançanas de oro es entendida sçiençia la qual ha muchas partes las quales son en el vergel de las esperidas, aquestas fueron fijas de atalante rey de greçia en el vergel de las quales fueron consagradas mançanas de oro a venus que era dios e fueron encomendadas a vn drago que las guardase aquestas donzellas segun fulgençio eran nonbradas [fol. LXXI'] ansi egrela esper medusa fetusa segun los latinos quieren dezir estudio entender remenbrar bien fablar.quieren dezir: que la persona sabia deue sacar del huerto o del vergel mui rico e deleitoso conuiene saber de las escripturas que son ordenadas a dios.deue sacar las dichas quatro cosas e synse aquestas no las avria.

Por el dragon es entendido deseo o plazer dessordenado de las cosas temporales el qual vieda toda buena çiençia aqueste deue ser repremido por la persona sabia.

Por tiçiberus atado con tres cadenas es entendida la nuestra voluntat que es atada por tres deseos desordenados segun que es dicho en la esposiçion de la fabla de orfeo quando fabla de las deesas del infierno.

Por bursides que era mal ostalero el qual mataua e destruya los ombres deue ser entendido que la persona sabia deue destruyr toda malisçia e punir los falsos ffechos por virtud de justiçia.

Por la ydra quemada con fuego es entendida enbidia la qual deue seer secada e consumada con fuego damor e de caridat.

Por el rio es entendida que la persona sabia e virtuosa deue arredrar de si e de los otros tanto como pueda todo periglo e departir las cosas que son ayuntadas en tener consejos e parlamientos de tractamientos malos e periglosos.

Por el gigante es entendido que deues menospreçiar e matar todo deseo terrenal, ca gigante segun los griegos quiere dezir tierra.

Por chat el ladron es entendida toda ynjuria e mal trattamiento fecho ascondida mente contra los otros.

Por el puerco se entiende todo pensamiento de suziedat e de vildat de gula e de luxuria.

Por lo que dize que sostouiese el çielo es entendido que deue buscar e 
poner el su entendimiento de su poderio en las cosas çelestiales por la qual cosa si lo faze sera puesto e dado lugar en el çielo entre los santos que son ansi commo estrellas.

Todos los dichos enxienplos e todas las dichas cosas son puestas ha prouar que las buenas personas e virtuosas e sabias no se deuen desmayar nin su coraçon derrocar por fortunas contrarias por fuertes que sean, mas deuelas sofrir vigorosa mente e virtuosa, ca final mente si las sufre bien aura aquello que justa mente desea e avn mucho mas por las quales cosas la philosophia ha despertado ha todas las gentes por tanto que alcançen el sobirano bien final. Dize ansi o varones [fol. $\mathrm{LXXI}^{v}$ ] sabes vos sabia mente e poderosa e virtuosa mente defender e non vos querades dexar derribar por las fortunas fuertes-si queres tener la carrera e el camino çelestial e tomad enxienplo del muy noble varon ercules. $\mathrm{O}$ vos otros locos e flacos e mesquinos e febles por que vos dexades desguarnir e mostrades las espaldas desguarnidas contra la batalla de la fortuna e vos dexais vençer a las cosas pequeñas e flacas e terrenales como podedes seer vençidos si vos no queres e ligera mente podres auer vitoria la qual si podedes ganar alçantaredes e auredes las cosas celestiales e perpetuales".

Las fuentes utilizadas para el apartado alegórico proceden básicamente de Fulgencio y el Mitógrafo Vaticano III, como puede comprobarse en el cotejo de los textos:

\section{Mythogr. III.13.5}

Hesperides, Atlantis filiae, regis Africae, hortum habuerunt, in quo erant mala aurea Veneri consecrata, quae Hercules, missus ab Eurystheo, occiso pervigili dracone, sustulit......

De hoc tamen figmento subtilius sentit Fulgentius. Quatuor enim, ait, Hesperides dicuntur Aegle, Hesperis, Medusa et Phaethusa, quas nos Latine studium, intellectum, memoriam et facundiam dicimus De harum horto aurea mala tollit Hercules, quia per has ad philosophiam pervenitur ${ }^{18}$

\section{Ms. 10.193}

«[fol. LXX] Por las milgranas o mançanas de oro es entendida sçiençia, la qual ha muchas partes las quales son en el vergel de las esperidas. Aquestas fueron fijas de Atalante rey de Greçia, en el vergel de las quales fueron consagradas mançanas de oro a Venus, que era dios, e fueron encomendadas a vn drago que las guardase. Aquestas donzellas segun Fulgençio eran nonbradas [fol. LXXI'] ansi Egrela, Esper, Medusa, Fetusa; segun los latinos quie-

18 El texto de Fulgencio es muy parecido al del Mitógrafo III. Se encuentra en la Expositio Virgilianae Continentiae secundum philosophos moralis (ed. R. Helm, Stuttgart, 1970, pág. 97) 
Fulgencio, III.XI.79

Fineus enim in modum auaritiae ponitur; a fenerando Fineus dictus est. Ideo cecus, quod omnis auaritia ceca sit quae sua non videt...... ren dezir estudio, entender, remenbrar, bien fablar. Quieren dezir que la persona sabia deue sacar del huerto o del vergel muy rico e deleitoso, conviene a saber de las escripturas....[fol. LXX'] a Fineo çiego por el qual es entendido el ome auariento, el qual es çegado por auariçia"......

\section{El Códice 10.220 Y ENRIQUe de Villena}

Al comienzo de nuestro estudio decíamos que no podiamos compartir la conclusión de R.G. Keightley en el sentido de que el comentario de Trevet, o derivado de él, utilizado por Villena en la redacción de Los doze trabajos de Hércules pudo estar relacionado con el atribuido a López de Ayala.

Para que tal hipótesis sea verosímil es necesario antes demostrar que la traducción castellana y las glosas que la acompañan fueron realizadas por el Canciller Ayala, porque en ese caso serian por lo menos diez años anteriores a la obra de Villena, dado que el Canciller muere en 1407 y Los doze trabajos se terminaron en 1417.

Es bien sabido por los estudiosos de la literatura medieval española que al comienzo de la traducción del códice 10220 se encuentra una carta ${ }^{19}$ en la que el condestable Ruy López de Avalos se dirige al traductor como "verdadero amigo" y a continuación la contestación de éste.

Amador de los Ríos ${ }^{20}$ basándose en el hecho de que Fernan Pérez de Guzmán $^{21}$ atribuye una traducción de Boecio a su tío el Canciller Ayala, cree que «no falta razón para suponer que es esta la traducción de Ayala, la cual se ha sospechado perdida».

y dice así.... nam et Hercules aurea mala de horto Hesperidum tollit; quattuor enim Esperides dictae sunt, id est Egle, esper, Medusa et Aretusa, quas nos Latine studium intellectus, memoria et facundia dicimus.

El texto del Mitógrafo procede de la edición de R. Helm, Mitologiarum libri tres, Stuttgart, 1970 , pág. 79.

19 Con esta traducción conocemos dos códices en la Biblioteca Nacional, el citado 10.220 y el 13.274, que comienza así: «Libro de la consolaçion natural de boeçio rromano. E comiença vna carta de Rruy Lopes de Daualos al que lo rromanço"

Por carecer de glosas no será tenido en cuenta en nuestro estudio.

${ }_{20}$ Obras de Don Inigo Lopez de Mendoza, Marqués de Santillana, Madrid, 1852, pág. 597.

${ }^{21}$ «Por causa del, son conoçidos algunos libros en Castilla que antes non lo eran, ansi como ... el Boeçio» (Generaciones y semblanzas, ed., R. B. Tate, Londres, 1965, pág. 15). 
Esta opinión es acogida también por M. Schiff ${ }^{22}$ y por el mismo Keightley ${ }^{23}$, si bien los estudiosos de la obra de Pero López de Ayala mantienen muchas reservas sobre dicha autoría, aunque tampoco aportan datos convincentes en su contra.

Así, tanto F. Meregalli ${ }^{24}$ como F. Branciforti ${ }^{25}$ excluyen su paternidad basándose en el examen de elementos externos como el que la contestación del traductor esté redactada en un estilo más latinizante que el acostumbrado por Ayala.

Por el contrario, para Michel García ${ }^{26}$ «la tonalidad de la obra de Boecio no choca con las preocupaciones filosóficas de Pero López, ni con la voluntad atribuida por los genealogistas a este autor de querer ennoblecer y enriquecer con sus traducciones a la nación castellanan. Con todo, este destacado investigador de la obra del Canciller piensa que ni en la carta ni en el prólogo «desgraciadamente nada permite ...identificar al autor».

Nosotros creemos, en cambio, que tanto en la carta de Ruy López de Dávalos y en la respuesta del anónimo traductor como en las glosas que se refieren a Hércules hay elementos de juicio para establecer, creemos que definitivamente, si López de Ayala fue o no el autor de la traducción de Boecio y de las glosas que la acompañan.

Estas son las glosas que se hallan en el códice 10.220 (fols. $99^{r}-100^{r}$ ):

"[fol. 99'] Hercoles de quien se faze aqui mençion fue fijo de Jupiter e de almena commo quier que algunos digan no aver contesçido a este todo lo que le atribuyen pero quier ansi sea o no al proposito presente no estorua, el qual es amonestar a los fuertes o virtuosos a la pelea con los viçios para alcançar la feliçidat desseada, trayendo exemplo de varones que sofrieron grandes trabajos por venir al cabo de sus desseos.

[fol. 99'] 1. los çentauros fueron fijos de Yxion e de juno segun se dixo en el verso ultimo del libro terçero. E tenian el medio cuerpo de cauallo e el medio de hombre e commo destruyessen muchas tierras peleo hercoles con ellos fasta los vençer. Algunos mato e otros fuyeron a los logares yermos.

[fol. 72 $2^{\mathrm{V}}$ Yxion fue uno de los gigantes el qual quiso yazer con juno y ella entrepuso vna de sus donzellas. Otros dizen que vna nuue de su figura,

${ }^{22}$ Op. cil. pág. 177.

Op. cit. pág. 191 .

24 La vida politica del Canciller Ayala, Varese-Milán, 1955, págs. 128-129.

23 "Regesto delle opere di Pero López de Ayala", en Saggi e ricerche in memoria di E. Gotti, Palermo, 1962, I, págs. 289-317.

${ }_{26}$ Obra y personalidad del Canciller Ayala, Madrid, 1983, págs. 208-210. 
donde resçebida la simiente se engendraron los çentauros e por este pecado le dieron los dioses tal pena que puesta su cabeça en vna rueda todo tiempo fuesse mouido muy apriessa en derredor.

2. vn leon muy brauo estaua en la ysla nemea que es en gresçia.entre otras bestias fieras que fazia grandes daños.de cuyo temor no passauan caminantes ni avie labranças e aquella comarca se despoblaua.al qual hercoles mato con la maça ferrada que traye e despojada la piel guarneçio las vñas e dientes con oro e traxola despues por cobertura.

3. Las aves dize por las tres arpias aelle ocçipite çeleno que tenia el cuerpo commo aves e las çabeças de donzellas. Otros dizen que eran muchas las quales sin ser fartadas comian los manjares del rey fineo e ensuziauan su mesma despues de çiego por el juyzio de los dioses.por que fizo quebrar los ojos a dos fijos suyos por acusaçion de la madrastra su muger diziendo que la avian querido forçar.aviendo ella tentado a cada vno dellos de malefiçio. Hercoles doliendose de la pena deste rey destruyo muchas dellas con su arco.a otras cerro en la yslas tropheas do despues eneas las fallo e ansi los dioses tornaron la vista a fineo e a sus fijos.

4. Las mançanas dize por que vn rey de libia llamado athalante con habundança de Riquezas ordeno un vergel para su plazer cuyos arboles $e$ fruto eran de oro.en el medio del estaua un arbol mas alto en que eran mançanas de grande valor.dizen algunos que era vna sola.la qual guardaua vn dragon.este vergel encomendo a las tres donzellas hesperides fijas de hespero su hermano sin cuya liçençia ninguno podia entrar en el.mas hercoles entro dentro e con grande dificultat tomo la dicha mançana al dragon e presentola a euristeo rey de los argolicos por esso dize el mas graue et cetera

5. Al ceruero que es el can portero de los infiernos saco hercoles quando periteo yua tomar a proserpina desseando casar con ella despues de robada por pluto Rey de los infiernos en la conpañia de theseo e otros mançebos los quales desçendiendo a la tomar fueron estoruados en la entrada por el dicho can que trago a periteo que yua delante e avn ansi fiziera a theseo sino por hercoles que lo tomo e saco fuera atado con fuertes cadenas e dize triple por que era de tres cabeças e ansi avia de ser la cadena

6. El brauo señor es a saber diomedes tornado de la çerca de troya fue alçado por el Rey de traçia e dandose a fechos reales mando criar cauallos con carnes de hombres por que fuessen mas valientes e fieros. E puesta gente por los caminos tomauan los estranjeros para los dar a los cauallos e quando no avie estraños matauan de los naturales tanto que ningunos osauan venir de fuera e los naturales fu yan.hercoles mouido a compassion remedio a esta crueldat despedaçando al señor, es a dezir diomedes, dandolo a sus cauallos por vianda.

7. La ydra era la serpiente de quien se dixo en el comienço de la prosa sexta deste quarto libro.la qual hercoles mato con fuego segun ende es dicho.

[cf. fol. $99^{v}$ ydra era vna serpiente con muchas cabeças que estaua en 
tierra de gresçia en vna laguna llamada lerne la qual fazia grandes daños.e por una cabeça que le cortauan nasçianle otras muchas.ansi que aviendo tal daño por syn remedio despoblase la tierra de aquel derredor.fasta que vino hercoles e prouo a la matar tajando las cabeças.e victo la su naturaleza mando juntar mucha leña en torno de la laguna e puesto fuego fue ardida la serpiente, por esso dizzen ni la manera et caetera.]

8. Achelous.fue uno de los gigantes con el qual se conbatio hercoles leuando a daymira a su tierra çerca la prouinçia de calidonia, la qual era despoblada este achelous.e commo hercoles le sobrasse en fuerças començo a vsar de encantaçiones que sabie tomando forma de serpiente. mas hercoles lo apretaua de la garganta tanto fuerte que lo afogara si no se mudara en forma de toro.enpero el lo tomo por los cuernos rodeandolo tan rezio que le quebranto el vno.por esso dize afeado en la frente. E ansi vençido escondiosse entre las peñas de vn rio que corrie çerca dende a la tierra se torno a poblar.

[fol. 100'] 9. Antheo fue vn varon en africa que por ligereza a fuerça vençia las bestias e honbres fueres e moraua en vna cueua desde la qual fazia tantos daños en la tierra de libia que los mercaderes e otras gentes se desuiauan de los puertos. Hercoles venido a la dicha cueua peleo con el luchando grande espaçio sin conosçerse ventaja.pero al fin vençia hercoles.mas antheo vso de vna virtud que tenia ca dezian ser fijo de la tierra e quantas vezes la tañia descansaua cobrando nueua fuerça. Ansi que dexandose caer en el suelo cuydaua hercoles que lo tenia vençido.mas leuantandose fallaualo al contrario.e faziendo esto algunas vezes barrunto hercoles la tal propiedat e asiendodolo por la çintura echose de espaldas en tierra en guisa que lo sostouo en el ayre apretandolo fasta que lo affogo.

10. Caco.vno de los çentauros fijo de Vulcano moraua en vna cueua del monte aventino que es en Roma el qual fazia muchos furtos e robos.hercoles tornando de españa donde vençiera a gerion sopo deste ladron e penso de lo matar e fue ansi por que de las vacas e puercos que hercoles leuaua de españa furto muchas sacandolas de los Rebaños rastrando por las colas por no dexar rastroderecho e para buscar el logar de la cueua mando hercoles rodear el monte con bezerros los quales bramando por las madres robadas fue conosçido el logar de la cueua por la repuesta de las vacas e llegando a la puerta caco se defendia sauçando fuegos pero al cabo fue vençido e muerto e por que el rey euandro auie venido de greçia con su madre e moraua en el dicho monte. Resçibiendo deste ladron mayores daños que otros ca estaua mas çerca e tenia muchos ganados.dize farto las yras euandro.

11. El puerco fue vno que cresçio en calidonia mientra despoblada por Achelous ante que hercoles lo vençiesse e era muy grande e fiero entre muchos animales criados ende durando la despoblacion e fazia tales daños que era grandes estoruo a los pobladores de aquella tierra. al qual hercoles mato en compañia de otros caualleros.ya sea que la virgen athalante le firio pri- 
mero, mas por que fue hercoles ordenador deste monte a le dio la ferida de que murio diosse la honrra desta victoria a el e por que las espumas e sangre del puerco llegaron a los onbros suyos en los quales sostuuo despues el çielo segun se dira en el siguiente trabajo.dize señaló con espumas.

12. El postrero trabajo de hercoles fue sostener el çielo en logar de aquel rey de libia llamado athalante de quien ariba es dicho en cuyo tiempo contesçio caerse de pedaços e doliendosse de tan ordenado e bien mouido cuerpo peresçer dexada la ministraçion del reyno trabajose en lo sostener con los onbros e duro ansi largo tiempo mas en fin no podiendo sostenerlo rogo a hercoles que suçediesse en tan loable affan a los dioses por ruego de ambos tornaron a atalante monte alto el qual agora se muestra en africa a la parte de occidente hercoles sobido ençima sostouo el çielo sin cansar avnque fue conbatido de los gigantes segun se dixo en la prosa dozena del libro terçero. Mas inclio la vna rodilla e en tal manera lo puso Jupiter en el çielo el qual meresçio por gualardon deste trabajo».

Si nos detenemos ahora, por ejemplo, en el cuarto trabajo tal y como es descrito por Villena en el apartado correspondiente a la Historia nuda ${ }^{27}$ observamos que no puede explicarse partiendo de las glosas latinas de Trevet ni siquiera de la Farsalia de Lucano (IX, vv. 355-367) a la que se refiere el mismo Villena en el citado apartado. Aquí, como en otros muchos pasajes, en tanto no encontremos una fuente más evidente, tendremos que hablar de creación o recreación por parte del autor castellano, es decir de alejamiento del modelo citado y sin duda utilizado.

Por el contrario, cotejando el texto del códice 10.220 y el correspondiente de Villena, se llega a la conclusión de que son tan parecidos que necesariamente uno tiene que depender del otro, ya que, como hemos anticipado, la fuente o fuentes latinas no pueden dar pie a dicha semejanza.

Veamos, en una lectura paralela, lo que dicen uno y otro en el cuarto trabajo:

Ms. 10.220 (fol. $99^{r}$ ) «Las mançanas dize por que vn rey de libia llamado athalante con habundança de riquezas ordeno un vergel para su plazer, cuyos arboles e fruto eran de oro. En el medio del estaua un arbol mas alto en que eran mançanas de grande valor. Dizen al-

\section{E. de Villena, pp. $39-40$} «Fue un rey en las parte de libia al qual dizian atalante e por abundançia de riquezas ordeno a su deleite un vergel cuyos arboles e fructos todos eran de oro... En medio de aqueste vergel era un arbol mas alto o mejor paresçiente que los otros. E

${ }^{27}$ Op. cit. págs. 39-40. 
gunos que eran de oro. En el medio del estaua un arbol mas alto en que eran mançanas de grande valor. $\mathrm{Di}$ zen algunos que era vna sola, la qual guardaua vn dragon; este vergel encomendo a las tres donzellas hesperides, fijas de hespero su hemano, sin cuya liçençia ninguno podia entra en el; mas hercoles entro dentro e con grande dificultat, tomo la dicha mançana al dragon en presentola a euristeo rey de los argolicos». alli era la mas fermosa e de mayor valia mançana, a cuyo defendimeinto un dragon grande... Todo este vergel a tres donzellas era encomendado ...Dizianles esperidas por se fijas de espero ermano que fue de atalante...; (ercules) entro en el maravilloso vergel...e tomo del arbol la rica mançana e presentola a euristeo rey de los argolicos...»

En cuanto al número de las Hespérides nótese que los citados pasajes mencionan tres en tanto que Trevet y una de sus versiones castellanas (ms. 174) hablan de siete, el códice 10.193 y el Mitógrafo Vaticano III se refieren a cuatro.

La misma impresión de estrechísima relación entre las glosas de códice 10.220 y Enrique de Villena obtendrá el lector si sigue cotejando los demás trabajos de Hércules.

Ninguno de los textos latinos conocidos, y nos atreveríamos a decir por conocer, ha podido servir de fuente común, por la sencilla razón de que entre la obra de Villena y la atribuida de Ayala hay una relación de dependencia entre ellas.

A primera vista todo parece indicar que nos encontramos ante un texto amplio, el de Villena, y un resumen de él, el que se halla en el códice 10.220.

Pero esta hipótesis solamente sería válida si se demostrase que el Canciller no fue el autor de la traducción ni de las glosas, porque en caso afirmativo una vez que hemos desechado la fuente común por indemostrable, de acuerdo con los datos de que disponemos, serían las glosas del manuscrito de la Biblioteca Nacional el modelo utilizado por Villena.

En este sentido, y contra la opinión formulada por M. Garcia, creemos que tanto en la carta como en su contestación hay elementos para, por lo menos, descartar a Ayala como autor de la traducción.

En efecto, Ruy López Dávalos dice en la carta introductoria que ya ha leido una traducción en la que la obra de Boecio se mezcla con las glosas de Trevet, pero esto mismo le ha dificultado aún más la comprensión del filósofo, y es por esto por lo que ruega al traductor que el texto vaya aparte de las notas o glosas: «Por esto pense con singular affection rogar a vos que trabaiassedes en traer a nuestra lengua vulgar la consolación del sancto dotor Seuerino, que por nombre propio es llamado Boeçio, el qual yo creo aber declarado cosas de muy grande prouecho. E commo quier que yo he 
leydo este libro romançado por el ffamoso maestro Nicolas, no es de mi entendido ansi commo querria. E creo que sea esto por falta de mi ingenio y aun pienso fazerme algun estoruo estar mesclado el texto con glosas, lo qual me trae una grand escuridat. E auria especial graçia me fuesse por vos declarado, en tal manera que mejor lo podiesse entender guardando las palabras con que el actor se rrasona, señalando en la margen lo que vuestro ingenio podiere para que yo syn conpañero el texto pueda entender... "

En ningun momento Dávalos pide al traductor que vuelva a repetir las glosas de Nicolás Trevet, sino «lo que vuestro ingenio podiere».

Este, en su contestación, se excusa de su inhabilidad, pero considera que no puede rechazar su mandato por lo que se pone manos a la obra: «E queriendo lleguar a la obra manifestauasse a mi mayor difficultat de lo acabar tanto que ya dexauade mirar al su comienço. E segun escriue Dante fingendo los espantos de la entrada infernal:

"ansy commo aquel que desquiere lo que quiere

e por nuevo pensamiento trueca lo propuesto,

ansy que del començamiento todo se quita».

Tal me sentia yo en esto que propusiera, enpero la obediençia que mucho me apremiara fazia dubdoso mi coraçon».

La cita que hace de Dante nos permite comprobar que este anónimo traductor de Boecio al castellano conocía la traducción de la Divina Comedia de Dante ${ }^{28}$, realizada precisamente por don Enrique de Villena, pues los versos anteriormente citados los tomó sin duda del Canto II, versos 13-15 de dicha versión:

"e asi como aquel que desquiere lo que quiere

e por nueuo pensamiento troca proposito

asi que de aquel començamiento todo se quita».

${ }^{28}$ Se encuentra en el ms. 10.186 de la B.N. de Madrid y ha sido magnificamente estudiada y editada por J. A. Pascual (La Traducción de la Divina Comedia atribuida a D. Enrique de Aragón. Estudio y edición del infierno. Universidad de Salamanca, 1974). Posteriormente el citado autor y R. Santiago Lacuesta publicaron un decisivo trabajo titulado "La primera traducción castellana de la Divina Commedia, argumentos para la identificación de su autor", Serta Philologica F. Lázaro Carreter, Madrid 1983, pág. 391-402. 
Queda, pues, definitivamente descartado como autor de la traducción de Boecio el Canciller Ayala, quien había muerto años antes de que Enrique de Villena llevase a cabo la traducción de la Divina Comedia de Dante.

Independientemente de quien haya podido ser el autor de la traducción, incluso cabría la remota posibilidad de que hubiese sido el propio don Enrique, lo que sí queda claro es que conocía Los doze trabajos de Hercules y La Divina Comedia en su traducción castellana.

Podemos, pues, concluir, que las glosas a los trabajos de Hércules que se encuentran en el códice 10.220 son un resumen, un compendio de la obra de Enrique de Villena.

Lo visto hasta aquí nos permite, además, valorar en su justa medida las propuestas de M. Morreale y R. G. Keightley. En efecto, don Enrique de Villena debió conocer las glosas de Nicolás de Trevet, alguna de las cuales posiblemente fue incorporada a su obra, pero también conoció y utilizó otras que le sirvieron como modelo para la interpretación alegórica, prácticamente ausente de Trevet.

Este stemma mostraría gráfica y escuetamente nuestras propuestas:

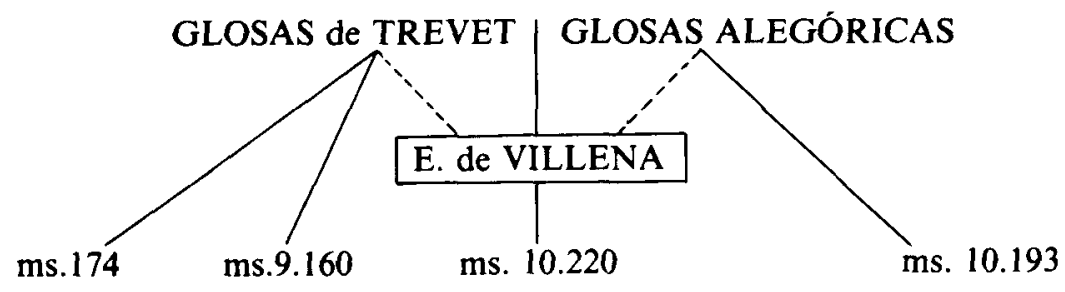

